\title{
The London Wetland Centre: An urban conservation project that is making a splash
}

James Harden*

London Wetland Centre, London, U.K.

\begin{abstract}
In the eleven years since it opened in 2000, the London Wetland Centre has become an exemplar of an urban conservation project that has turned heads throughout the world. As we shall explore, a site has been created that now has international recognition for its scientific interest, and which provides an ideal case study for how biodiversity and sustainability can be achieved, even in the challenging economic landscapes that are associated with the twenty-first century.
\end{abstract}

\section{The Vision}

The London Wetland Centre (Centre) is based in south-west London, less than 8 miles from Westminster Abbey, and adjacent to the River Thames. It is a 105 acre site managed by the Wildfowl and Wetlands Trust, a charity with the specific and vital remit of conserving wetlands.

The Trust was established in 1946 by Sir Peter Scott, and now manages nine wetland sites in the UK, which receive over a million visitors per annum. The Trust also has a membership totalling 200,000 and is able to significantly influence the conservation agenda. 


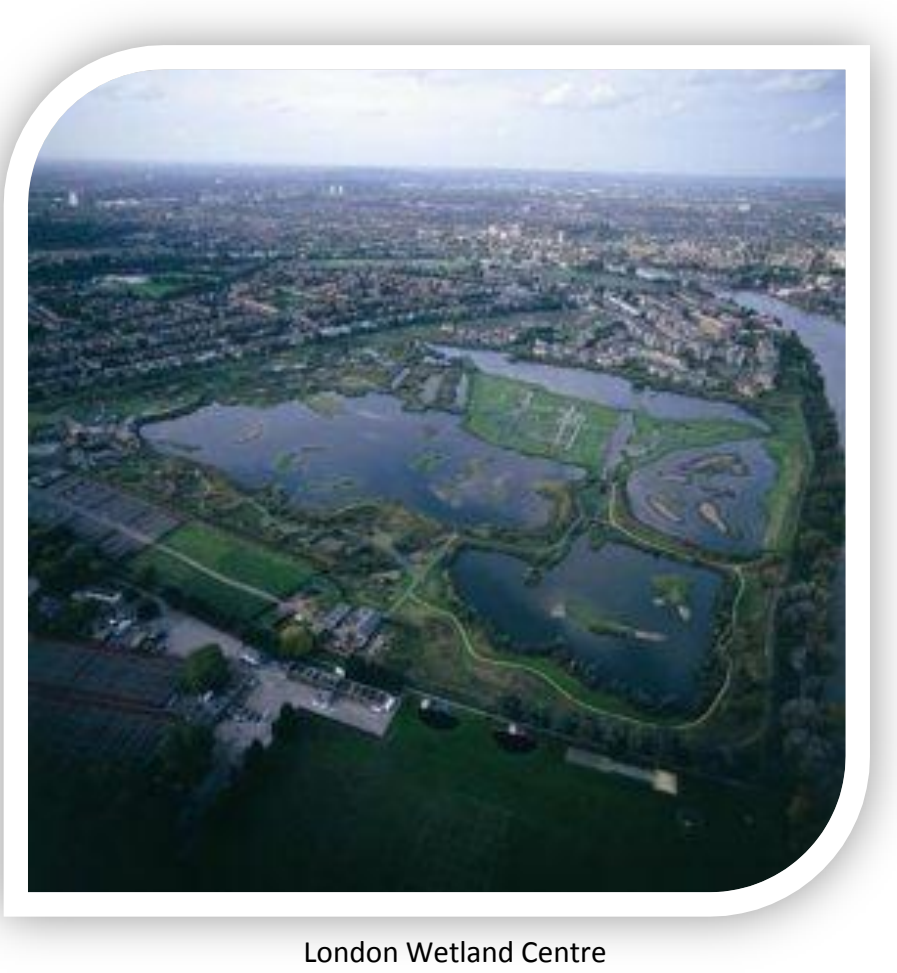

Sir Peter Scott himself was the son of Captain Robert Falcon Scott or "Scott of the Antarctic," and it is interesting to observe that the will of the polar explorer insisted that an interest in wildlife should be fostered in his one and only child.

The creation of an urban wetland site had long been the aspiration of Sir Peter, and in the 1980s he recognised the potential of the site then known as Barn Elms Reservoirs. The reservoirs had been created in the late nineteenth century, at the time

of the industrial revolution, to provide drinking water to the rapidly growing population of London. However, due to their non-compliance with European Union (EU) regulations, they had become redundant, and were ostensibly a financial burden to the Water Company (Thames Water), as the site had to be kept secure. Furthermore, as the site had already been recognised as a Site of Special Scientific Interest (SSSI) on account of its importance to diving ducks, legislation dictated that the site would have to be maintained as a water body.

\section{Securing the Financial Backing}

Having identified a site that could be developed, it is testament to Sir Peter's skills in negotiation that he was able to secure it for free from Thames Water, but of course there was still a need to source the funds to transform the site into the bio-diverse habitat that represented his vision. This was enabled by selling a small section of the site to a property developer, Berkeley Homes, for the sum of $£ 11$ million, whilst the remaining f,5 million was obtained through a series of donations and grants. It is a story which nicely illustrates the need for conservation to be married to pragmatism: the sacrificing 
of even a small part of the site would have been a difficult decision, yet the funds raised by the sale no doubt leveraged the support from funders and private donors.

Whilst $f_{16}$ million is not an insignificant investment, it compares very favourably with the $f_{789}$ million associated with the establishment of the 'Dome' - the UK's Millennium Experience - that was funded in no small part by the taxpayer. The London Wetland Centre perfectly illustrates, therefore, that well managed conservation projects can have genuine 'added value'.

\section{Development of the Site}

Site construction began in 1995 and tight planning regulations ensured that sustainability remained at the forefront of the minds of the project team. Recycling was necessitated by the planning regulation that insisted that no spoil (with the exception of basic building materials) was to be allowed to be removed from the site. On that basis, the concrete lining to the reservoir was broken up and used to create paths and the car park. Some 1.6 million cubic feet of soil was sorted and re-mixed, the water bodies were contoured, and islands and other landscape features were created. Meanwhile, some 300,000 aquatic plants were introduced and the key vegetation communities were established. No opportunity to increase the space for wildlife was wasted, and many of the bird hides were constructed with a roof upon which vegetation was planted.

In May 2000, the Centre was opened: a habitat had been created that was fit for Reed Warblers to breed, where the exceptionally rare Bittern could over-winter, where butterflies and bees could obtain nectar, and with a richness of insect-life that now supports up to eight species of bat.

In 2001, the Centre received the accolade of being a winner of a British Airways Global Award for sustainable ecotourism.

Since that time, the Centre has continued to adopt a pro-active stance towards promoting sustainability, as can be demonstrated by the opening of its Rain Garden in 2010. Water conservation will become increasingly important as the climate changes, and the garden emphasises the importance of harnessing rain water, as opposed to allowing it to run-off from impermeable surfaces and potentially contribute to flooding and erosion. Recycling is another theme that is promoted, as the centrepiece of the garden is an old shipping container planted with a green roof, providing an elevated wildlife habitat.

ECJ Volume 1, No. 1, 2011 


\section{Education}

It is recognised by the Centre that engaging with future generations at an early stage in their development is key if conservation and sustainability are to be concepts that are understood and embraced. The Centre has a dedicated team to promote this agenda and strives to be innovative: it has a conservation-themed adventure playground, a ponddipping zone, interactive exhibits, and boasts a captive collection of wildfowl that reflects the diversity of ducks, geese, and swans. There are also special events on a daily basis that help make the Centre a lively and educational day out for even the younger members of the family.

\section{Has it been a success?}

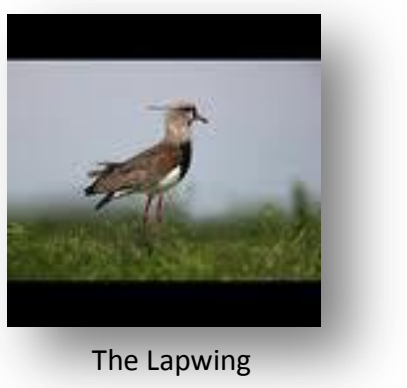

In a word, yes. The wildlife of the site could form the contents of a publication in its own right, but it is worth reflecting on some of the key species that have colonised the site. The Lapwing is a bird that has experienced a national decline in recent years and has not bred in London since before the War; yet several pairs now raise their young each year. The site is now one of the top sites in south-east England to view over-wintering Bitterns and some six individuals were present in winter 2010/11; prior to the establishment of the Centre, it would have been over 100 years since this rare heron-like species had been recorded so close to the centre of London.

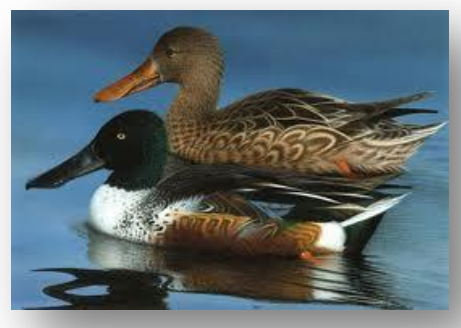

The Shoveler Duck species such as Shoveler and Gadwall are present in numbers of national significance.

Meanwhile the site is in the top 5\% in London for observing bats, and hosts about twenty dragonfly and damselfly species.

Furthermore, the Centre has played a key role in some successful reintroduction programmes. The Water Vole population in the UK had declined by some $90 \%$ since the 1960 s, primarily due to the unsympathetic management of watercourses, but also as a result of predation by the American Mink. A population of 250 Water Voles was released into the Centre in 2001, which has now established and flourished to between 
300-400 individuals. Other reintroduction projects involve a species of legless lizard known as the slow worm, and the Tower Mustard plant.

\section{The Future}

At only 11 years old, the site is still a young one, and careful management should ensure that it continues to attract new animal and plant species. It is a model for urban conservation which has been recognised around the world, and earlier this year, I had the privilege of introducing the site to a conservationist from Finland, who has been tasked with the creation of a comparable site in Helsinki. As per the old adage: "imitation is the sincerest form of flattery."

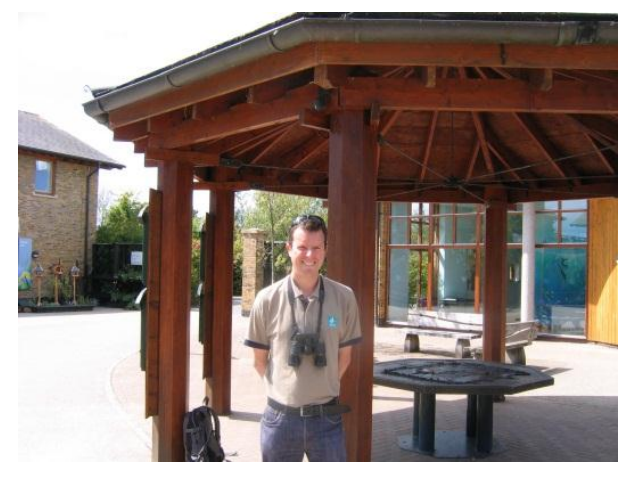

* Author: James Harden received training in Biology with Environmental Studies at the University of London, and works for a biomedical research charity in London. At the weekend, he likes to escape the stresses of his day job by serving as a volunteer at the London Wetland Centre, where he uses his knowledge of the site and wildlife to conduct tours. James has been a birdwatcher for over 20 years, and was a visitor to the site in its previous life as a complex of reservoirs.(email:jamesharden@,tiscali.co.uk) 